\title{
Analysis of Tracheal Secretion in Healthy Horses Undergoing a Vaquejada Simulation Test
}

\author{
Natália Matos Souza Azevedo1*, Márlon de Vasconcelos Azevedo1, \\ Paulo Fernandes de Lima1, Hélio Cordeiro Manso Filho \\ ${ }^{1}$ Departamento de Medicina Veterinária, Universidade Federal Rural de Pernambuco, Recife, Brazil \\ ${ }^{2}$ Departamento de Zootecnia, Universidade Federal Rural de Pernambuco, Recife, Brazil \\ Email: ${ }^{\text {nataliams vet@hotmail.com }}$
}

Received 23 August 2014; revised 11 September 2014; accepted 9 October 2014

Copyright (C) 2014 by authors and Scientific Research Publishing Inc.

This work is licensed under the Creative Commons Attribution International License (CC BY).

http://creativecommons.org/licenses/by/4.0/

c) (†) Open Access

\section{Abstract}

This study aimed to evaluate the occurrence of EIPH in vaquejada horses via endoscopy and tracheal lavage and citology. We used eight Quarter-mile horses that usually perform at vaquejadas. Clinical examination was carried out before the race. After the race, endoscopy and tracheal lavage with $20 \mathrm{ml}$ of saline via the service channel of the endoscope were performed. The samples were sent to the laboratory for processing and confection of the slides. Of the eight horses (four pull and four helper horses), six had hemosiderophages in their tracheal aspirates, confirming the existence of pulmonary hemorrhage after exercise. No difference was observed between the analyzed parameters between the two groups of vaquejada horses $(P>0.05)$. Tracheal lavage and endoscopy can be used for evaluating this important disease in animal athletes.

\section{Keywords}

\section{EIPH, Horses, Sport, Endoscopy}

\section{Introduction}

Respiratory diseases have been identified as one of the main causes of interruption in the training and competition of pure-blooded racehorses [1]. Inflammatory airway disease (IAD) and exercise-induced pulmonary hemorrhage (EIPH) are two common issues that affect the lower airways of racehorses, resulting in a poor performance [2].

${ }^{*}$ Corresponding author.

How to cite this paper: Souza Azevedo, N.M., de Vasconcelos Azevedo, M., de Lima, P.F. and Filho, H.C.M. (2014) Analysis of Tracheal Secretion in Healthy Horses Undergoing a Vaquejada Simulation Test. Open Journal of Veterinary Medicine, 4, 232-238. http://dx.doi.org/10.4236/ojvm.2014.410027 
Inflammatory airway disease (IAD) is associated with a low performance and accumulation of mucus and inflammatory cells in the airways. Horses with IAD often have an increased relative neutrophil count in their bronchoalveolar lavage (BAL), and less frequently, the relative count of eosinophils and/or mast cells can be increased. The etiopathogenesis of IAD is unknown, but may involve individual factors and/or acquired immune responses to several factors, including breathable components, such as dust, microorganisms, harmful gases, and air conditioning [3].

The prevalence for IAD in racehorses has been reported as being between $11.2 \%$ and $50 \%$ [4]-[6]. This disease is prejudicial to athletic performance [7] [8] and is an important cause of losses in the equine industry [9]. Diagnosis is usually obtained by endoscopy of the trachea, where increased production of mucus and pus is observed, and cytology from the tracheal wash or bronchoalveolar lavage (BAL) of the lower respiratory tract [10] [11].

Exercise-induced pulmonary hemorrhage (EIPH) is a prevalent syndrome in horses, with repeated episodes of hemoptysis after exaggerated exercise [12]. Despite its high prevalence (43.8\% - 75.4\%), little is known about the predisposing factors that lead to EIPH [13]-[15]. Part of the difficulty in determining its pathophysiology and treatment is lack of precision regarding diagnostic methods.

Epistaxis alone has a low specificity and sensibility for detection of EIPH in horses. Endoscopy of the tracheobronchial airways currently remains the most accepted method for detecting EIPH 30 to 90 minutes after exercise. Nevertheless, it is still difficult to obtain a true positive [16]. Cytology of the tracheal lavage (TL) is considered more specific than only an endoscopy exam, being described as a tool for diagnosing pulmonary disease [17]. However, cytology becomes fundamental because it allows the observation of cells that are characteristic of a hemorrhagic process, such as hemosiderophages [16] [18] [19].

Our objective was to analyze the tracheal secretion from healthy horses submitted to a vaquejada simulation test via endoscopy and tracheal lavage and subsequent cytology.

\section{Material and Methods}

This study has the approval of the Ethics Committee of the UFRPE under protocol number 23082.004734/2013. Eight Quarter mile horses were selected (four pull and four helper horses), two females and six males, with ages between 3 and 18 years (mean 10.5 years). A physical examination, which included heart and respiratory rates, temperature, capillary refill time, intestinal motility, and lung auscultation, was performed in all horses before the test. Mean velocity was obtained by dividing the distance traveled by the mean time.

Simulation of the vaquejada was comprised of five runs with the pull horses and the helper horses with the use of a bull. In the conventional competition, there are three runs before the horse can go to the following level of the course. As most horses pass this first phase, we decided on five runs so that the number of runs would not be over or underestimated.

For endoscopy, the horses were contained with the help of a twitch. The endoscope that was used was an OLYMPUS CF Type EL (9 mm external diameter, $2.8 \mathrm{~mm}$ working channel, and $103 \mathrm{~cm}$ length). Endoscopy was performed 30 to 60 minutes after exercise, where the respiratory tract was evaluated from the nasal meatus to the trachea for the presence of secretion (color, quantity, and localization), hyperemia of the mucosa, and changes to the respiratory tract observable via endoscopy. Secretions observed on endoscopy were attributed scores from 1 to 5 [20].

For the tracheal lavage, the endoscope, with a catheter for transendoscopic sample collection (MILA ${ }^{\circledR}$ Delivery Catheter) in its working channel, was introduced via the ventral nasal meatus towards the trachea. The catheter was positioned in the distal portion of the trachea, anterior to the carina, in accordance with a previously described technique [21]. For the TL, $20 \mathrm{ml}$ of sterile saline were instilled with the use of sterile plastic syringes $\left(\right.$ Injex ${ }^{\circledR}$ ) and immediately aspirated. The samples were considered adequate when suspended particles or mucus filaments were observed. The lavage was refrigerated in the same syringe used for collection until processing.

Aliquots of the lavage $(20 \mathrm{~mL})$ were centrifuged at $110 \mathrm{~g}$ for $5 \mathrm{~min}$ in a $\mathrm{RDE}^{\circledR} \mathrm{MC}-16$ centrifuge. The supernatant was discarded and the sediment of cells used to prepare slides using a linear smear technique [22]. The slides were fixed in methanol for 5 minutes and stained using the May-Grumwald-Giemsa method.

For differential cell analysis, 100 cells were counted using the $1000 \mathrm{X}$ objective lens [23], differentiating the various cell types (epithelial cells, macrophages, lymphocytes, neutrophils, eosinophils, and hemosiderophages).

Descriptive statistics was initially used for analysis of the studied parameter, followed by the T-test to com- 
pare the means between the two groups of vaquejada horses (pull horses and helper horses). Results are shown in mean $+/-$ mean standard error. The software used for calculations was SigamaStat ${ }^{\circledR}$.

\section{Results}

Mean differential cell count from the tracheal aspirate showed $45.375 \pm 8.255$ epithelial cells; 0 caliciform cells; $25 \pm 9.59$ neutrophils; $4.25 \pm 1.013$ lymphocytes; $0.25 \pm 0.164$ eosinophils; $11.5 \pm 5.510$ foamy macrophages; $5.875 \pm 2.020$ hemosiderophages, and $0.87 \pm 0.743$ giant cells (Table 1 ).

Observations: mean values in the same row followed by different letters indicate that $\mathrm{P}<0.05$ using T-test. HR: Heart rate; RR: Respiratory rate; LTr: Recovered tracheal lavage; HSF: Hemosiderophages; ME: Foamy macrophages; GC: Giant cells.

Endoscopy, performed from 30 to 60 minutes after the test, revealed tracheal secretion in five of the eight horses. The secretions visible on endoscopy were classified according to the score from 1 - 5 [20]. Horses 1, 2, and 8 had secretion with grade 1 coloration and grade 2 quantity. Horse number 3 had secretion grade 1, coloration grade 1 . Horse 6 had secretion grade 1 and grade 3 coloration. All were located on the second third of the trachea. Results were organized into a table (Table 2). In horses 1 through 5, the trachea and carina were hyperactive, the mucosa hyperemic, but none had bleeding.

Regarding the changes of the upper airways of the respiratory tract, the presence of epiglottic chondritis was observed in horse number 4 , lymphoid follicular hyperplasia in horse 5 , dorsal dislocation of the soft palate in horse number 6 , and laryngeal hemiplegia in horse 8.

Sedation was not necessary for clinical exam or endoscopy. All horses were considered clinically normal and had no complaints of reduced performance. According to the physical exam performed before the test, heart rate was $46.5 \pm 4.732$ beats per minute and $33.75 \pm 3.369$ respirations per minute. During the test, the horses had a mean velocity of $40.11 \mathrm{Km} / \mathrm{h}$, and no animal was observed to have epistaxis or nasal mucus secretion on external examination. The amount of saline aspirated for the tracheal lavage was $18.875 \pm 0.639$. There were no differences between pull and helper horses for the analyzed parameters $(\mathrm{P}>0.05)$.

Table 1. Mean values for the studied parameters in pull and helper horses undergoing vaquejada test, municipality of Itabaina-PB.

\begin{tabular}{ccc}
\hline & & \\
Parameter & Types of Horses & Helper horses (4) \\
\cline { 2 - 3 } HR & $42.800 \pm 4.363 \mathrm{bpm}$ & $52.667 \pm 10.729 \mathrm{bpm}$ \\
RR & $30.800 \pm 3.929 \mathrm{mrpm}$ & $38.667 \pm 5.925 \mathrm{mrpm}$ \\
Velocity & $32.66 \pm 0.237 \mathrm{Km} / \mathrm{h}$ & $38.57 \pm 0.230 \mathrm{Km} / \mathrm{h}$ \\
LTr & $19.600 \pm 0.400 \mathrm{ml}$ & $17.667 \pm 1.453 \mathrm{ml}$ \\
\% Epithelial Cells & $38.800 \pm 10.293$ & $56.333 \pm 13.667$ \\
Caliciform Cells & 0 & 0 \\
Neutrophils & $37.200 \pm 12.575$ & $4.667 \pm 0.667$ \\
Lymphocytes & $4.600 \pm 1.400$ & $3.667 \pm 1.667$ \\
Eosinophils & $0.400 \pm 0.245$ & 0 \\
Total & $12.400 \pm 3.326$ & $31.00 \pm 13.577$ \\
Macro HSF & $4.00 \pm 2.811$ & $9.00 \pm 2.082$ \\
Macro ME & $7.800 \pm 3.367$ & $17.667 \pm 14.667$ \\
Macro GC & $0.200 \pm 0.200$ & $2.00 \pm 2.00$
\end{tabular}

Observations: mean values in the same row followed by different letters indicate that P < 0.05 using T-test. HR: Heart rate; RR: Respiratory rate; LTr: Recovered tracheal lavage; HSF: Hemosiderophages; ME: Foamy macrophages; GC: Giant cells. 
Table 2. Endoscopy findings and changes observed in the tracheal aspirate of vaquejada horses, Itabaiana-PB.

\begin{tabular}{|c|c|c|c|c|c|c|c|c|}
\hline \multirow[b]{2}{*}{ Horse } & \multicolumn{4}{|c|}{ Upper Airways } & \multicolumn{4}{|c|}{ Lower Airways } \\
\hline & HFL & Epiglottis & DDPM & $\begin{array}{c}\text { Laryngeal } \\
\text { hemiplegia }\end{array}$ & $\begin{array}{l}\text { Tracheal } \\
\text { Secretion }\end{array}$ & Trachea & Carina & $\begin{array}{c}\text { Pulmonary } \\
\text { bleeding }\end{array}$ \\
\hline 01 & - & - & - & - & $1-2-2 / 3$ & HR 4 & $\mathrm{HE}$ & - \\
\hline 02 & - & - & - & - & $1-2-2 / 3$ & HR 4 & HE & - \\
\hline 03 & - & - & - & - & $1-1-2 / 3$ & HR 4 & $\mathrm{HE}$ & - \\
\hline 04 & - & Chondritis & - & - & - & HR 4 & $\mathrm{HE}$ & - \\
\hline 05 & Grade II & - & - & - & - & HR 4 & $\mathrm{HE}$ & - \\
\hline 06 & - & - & $\mathrm{X}$ & - & $1-3-2 / 3$ & - & - & - \\
\hline 07 & - & - & - & - & - & - & - & - \\
\hline 08 & - & & - & Grade III & $1-2-2 / 3$ & - & - & - \\
\hline
\end{tabular}

HR: Hyperreactive, reddish coloration; HE: Hyperemic.

\section{Discussion}

History, clinical exam, endoscopy of the respiratory tract, and cytology of the tracheal lavage are valuable tools for investigating respiratory disease [24]. In the current study, we observed that, among these, cytology of the tracheal lavage is the most effective method for diagnosis, for there were no changes on physical exam, clinical history, or even endoscopy that would justify the cytology profile observed in these animals.

The tracheal lavage (TL) can be obtained during endoscopy of the airways, during which the structures of the respiratory tract as well as quantity of mucus can be evaluated. The quantity of mucus is directly related to inflammation of the airways and decreased performance in athlete horses [25]. The presence of mucus in the lower airways means a neutrophilic inflammation was probably involved; however, the absence of mucus does not exclude pulmonary inflammation, which may have been secondary to the accumulation of cells in the lower airways [26]. In this study, TL was easily performed, and $20 \mathrm{ml}$ of saline was infused, of which a mean of $18.875 \pm$ $0.639 \mathrm{ml}$ were recovered. We were also able to observe mucus in five of the eight horses, who also showed an increase in neutrophils, suggesting IAD.

It is important that cytology of the airways be a part of the routine clinical examination in equines, since respiratory disorders have a significant role in the health and performance of horses of all ages and participating in various sports [27].

Also, IAD and EIPH can be hard to identify clinically and can cause an important deficit to athletic performance by exacerbating the hypoxia induced by exercise [28]. The diagnosis, severity, and prognosis, as well as prevalence of presentations such as IAD and EIPH depend on cytology so that incomplete or wrong diagnosis are not made [11] [16] [29].

According to previously published reference values for cell types [2] found in the tracheal lavage, we observed that pull horses had an elevated mean quantity of neutrophils, eosinophils, and hemosiderophages, proving that though the horses were apparently asymptomatic, their cytology results were compatible with IAD and EIPH. Helper horses also had an increase in hemosiderophages, confirming the presence of EIPH.

Racehorses would probably also have some degree of pulmonary hemorhage during exercise, however, only $1 \%$ have epistaxis, while $50 \%$ are positive on endoscopy, and $100 \%$ are positive on BAL (bronchoalveolar lavage) [30]. Our study confirms the findings of a previous study, since none of the eight examined animals were positive via endoscopy and six had hemosiderophages, which confirms some degree of post-exercise bleeding [30]. Of the six horses that showed hemosiderophages, four are considered positive for hemorrhage because the percentage observed was higher than $5 \%$. Of these, three were helper horses and one was a pull horse.

In a similar manner, hemosiderophages were observed in the tracheal lavage of $86 \%$ of racehorses [31]. The high rate in which hemosiderophages were seen on cytology was already expected, since all equines submitted to exaggerated exercise suffer some kind of pulmonary hemorrhage [21]. 
Considering also that the hemorrhage is commonly located is the caudal lung lobe, it is likely that the TL presents a more diluted material than the BAL when we consider the presence of hemosiderophages [32]. Therefore, it is possible that in the present study, the presence of EIPH is being underestimated because of the use of TL instead of BAL.

The percentage of neutrophils in the airways of healthy horses should be $<20 \%$ of the total for the TL [25] [33]. In this study, all four pull horses $(4,5,7,8)$ had an increase in the percentage of neutrophils and eosinophils, and one of these had lymphoid follicular hyperplasia (animal 5), reinforcing the presence of a viral infection. Horse 6 had a large number of macrophages and giant cells, probably due to the presence of coccoid bacilli, which would lead these cells to divide rapidly to fight off the infection. Their increase is an important finding in the inflammatory process of the lungs [34] and at the same time represents a type Th2 immune response [35] since giant cells are not frequently seen in the tracheal lavage [25].

Although endoscopy is an easily performed exam, it is still little used routinely. In a previous study with 100 horses, 22 underwent endoscopy, of which 20 had a tracheal sample collected for cytology [24]. Endoscopy is the only method capable of identifying functional disorders of the upper respiratory tract [36] [37].

Endoscopy of 510 equines after exercise showed that $58.21 \%$ of the horses had obstructive diseases of the upper respiratory tract, with $17.80 \%$ having more than one obstructive condition [38].

On our endoscopy exams, we were able to observe functional changes to the upper respiratory tract, such as laryngeal hemiplegia, epiglottic chondritis, and dorsal dislocation of the soft palate. Furthermore, the exam was of fundamental importance because it allowed us to visualize the tracheal mucosa and to localize and quantify existing secretions.

Endoscopy can also help in estimating the severity of the EIPH through the quantity of blood present in the airways, since epistaxis is only seen in 0.25 to $13 \%$ of thoroughbred racehorses with EIPH [39]. However, in our study, we did not observe any pulmonary hemorrhage via endoscopy, which highlights the importance of performing a cytology of the tracheal lavage, without which there would be false negatives for EIPH.

In this study, clinical evaluation did not show relevant changes, since all horses were healthy and clinically normal. It has been established that normal heart rate and respiratory rate prior to exercise do not exclude the possibility of horses having some degree of pulmonary bleeding [40].

As in other studies, chemical restraint was unnecessary during endoscopy, and only a twitch was sufficient [41].

\section{Conclusions}

Endoscopy and cytology of the tracheal lavage are fundamental tools for the diagnosis of respiratory diseases, since endoscopy permits the identification of functional disorders and cytology, and the visualization of the predominant cell type, allowing an identification of the existing process as EIPH or IAD.

Larger studies are required in order to determine the occurrence of exercise-induced pulmonary hemorrhage and inflammatory airway disease in horses used in vaquejada, seeing as this is a sport that has differences when compared with other modalities, which may lead to different diseases.

\section{References}

[1] Wilsher, S., Allen, W.R. and Wood, J.L. (2006) Factors Associated with Failure of Thoroughbred Horses to Train and Race. Equine Veterinary Journal, 38, 113-118. http://dx.doi.org/10.2746/042516406776563305

[2] Richard, E.A., Fortier, G.D., Lekeux, P.M. and Erck, E.V. (2010) Laboratory Findings in Respiratory Fluids of the Poorly-Performing Horse. The Veterinary Journal, 185, 115-122. http://dx.doi.org/10.1016/j.tvjl.2009.05.003

[3] Hughes, K.J., Nicolson, L., Costa, N., Franklin, S.H., Allen, K.J. and Dunham, S.P. (2011) Evaluation of Cytokine mRNA Expression in Bronchoalveolar Lavage Cells from Horses with Inflammatory Airway Disease. Veterinary Immunology and Immunopathology, 140, 82-89. http://dx.doi.org/10.1016/j.vetimm.2010.11.018

[4] McNamara, B., Bauer, S. and Lafe, J. (1990) Endoscopic Evaluation of Exercise Induced Pulmonary Haemorrhage and Chronic Obstructive Pulmonary Disease in Association with Poor Performance in Racing Standardbreds. Journal of American Veterinary Medical Association, 196, 443-445.

[5] Burrell, M.H., Wood, J.L., Whitwell, K.E., Chanter, N., Mackintosh, M.E. and Mumford, J.A. (1996) Respiratory Disease in Thoroughbred Horses in training: The Relationships between Disease and Viruses, Bacteria and Environment. Veterinary Record, 139, 308-313. http://dx.doi.org/10.1136/vr.139.13.308 
[6] Wood, J.L.N., Newton, J.R., Chanter, N. and Mumford, J.A. (2005) Inflammatory Airway Disease, Nasal Discharge and Respiratory Infections in Young British Racehorses. Equine Veterinary Journal, 37, 236-242. http://dx.doi.org/10.2746/0425164054530579

[7] Couetil, L.L., Rosenthal, F.S., De Nicola, D.B. and Chilcoat, C.D. (2001) Clinical Signs, Evaluation of Bronchoalveolar Lavage Fluid, and Assessment of Pulmonary Function in Horses with Inflammatory Respiratory Disease. American Journal of Veterinary Research, 62, 538-546. http://dx.doi.org/10.2460/ajvr.2001.62.538

[8] Sanchez, A., Couetil, L.L., Ward, M.P. and Clark, S.P. (2005) Effect of Airway Disease on Blood Gas Exchange in Racehorses. Journal of Veterinary Internal Medicine, 19, 87-92. http://dx.doi.org/10.1111/j.1939-1676.2005.tb02663.x

[9] Bailey, C.J., Reid, S.W., Hodgson, D.R. and Rose, R.J. (1999) Impact of Injuries and Disease on a Cohort of Two- and Three-Year-Old Thoroughbreds In training. Veterinary Record, 145, 487-493.

[10] Moore, B.R., Krakowka, S., Robertson, J.T. and Cummins, J.M. (1995) Cytologic Evaluation of Bronchoalveolar Lavage Fluid Obtained from Standard Bred Racehorses with Inflammatory Airway Disease. American Journal of Veterinary Research, 56, 562-567.

[11] Couëtil, L.L., Hoffman, A.M., Hodgson, J., Buechner-Maxwell, V., Viel, L., Wood, J.L.N. and Lavoie, J.P. (2007) Inflammatory Airway Disease of Horses. Journal of Veterinary Internal Medicine, 21, 356-361. http://dx.doi.org/10.1111/j.1939-1676.2007.tb02975.x

[12] Roberts, C., Hillidge, C. and Marlin, D. (1993) Exercise-Induced Pulmonary Haemorrhage in Racing Thoroughbreds in Great Britain. International EIPH Conference, Ontario, 21-22.

[13] Pascoe, J.R., Ferraro, G.L., Cannon, J.H., Arthur, R.M. and Wheat, J.D. (1981) Exercise-Induced Pulmonary Hemorrhage in Racing Thoroughbreds: A Preliminary Study. American Journal of Veterinary Research, 42, 703-707.

[14] Raphael, C.F. and Soma, L.R. (1982) Exercise-Induced Pulmonary Hemorrhage in Thoroughbreds after Racing and Breeding. American Journal of Veterinary Research, 43, 1123-1127.

[15] Newton, J.R. and Wood, J.L. (2002) Evidence of an Association between Inflammatory Airway Disease and EIPH in Young Thoroughbreds during Training. Equine Veterinary Journal, 34, 417-424. http://dx.doi.org/10.1111/j.2042-3306.2002.tb05459.x.

[16] Doucet, M.Y. and Viel, L. (2002) Clinical, Radiographic, Endoscopic, Bronchoalveolar Lavage and Lung Biopsy Findings in Horses with Exercise-Induced Pulmonary Hemorrhage. Canadian Veterinary Journal, 43, 195-202.

[17] Dixon, P.M., Railton, D.I. and McGorum, B.C. (1995) Equine Pulmonary Disease: A Case Control Study of 300 Referred Cases. Part 1: Examination Techniques, Diagnostic Criteria and Diagnoses. Equine Veterinary Journal, 27, 416421. http://dx.doi.org/10.1111/j.2042-3306.1995.tb04421.x

[18] Hodgson, J.L. and Hodgson, D.R. (2003) Tracheal Aspirates: Indications, Technique and Interpretation. In: Robinson, N.E., Ed., Current Therapy in Equine Medicine, Saunders, St. Louis, 401-406. http://dx.doi.org/10.1016/B978-0-7216-9540-2.50130-4

[19] Biava, J.S., Gonçalves, R.C., Biondo, A.W. and Telles, J.E.Q. (2008) Escore total de hemossiderófagos (THS) na hemorragia pulmonar induzida por exercício (EIPH) em cavalos quarto de milha. Revista Acadêmica Ciências Agrárias Ambientais, 6, 335-340.

[20] Holcombe, S.J. (2005) Epidemiology of Airway Inflammation and Mucus in Horses. American Association of Equine Practitioners, 51, 337-340.

[21] Whitwell, K.E. and Greet, T.R.C. (1984) Collection and Evaluation of Tracheobronchial Washes in the Horse. Equine Veterinary Journal, 16, 499-508. http://dx.doi.org/10.1111/j.2042-3306.1984.tb02000.x

[22] Cowell, R.L. and Tyler, R.D. (1992) Diagnostic Cytology and Hematology of the Horse. Mosby, St. Louis.

[23] Hewson, J. and Viel, L. (2002) Sampling, Microbiology and Cytology of the Respiratory Tract. In: Lekeux, P., Ed., Equine Respiratory Diseases, Saunders, St. Louis.

[24] Szenci, O., Orsolya K., Balogh N., Lajos Z. and Nagy K. (2011) Diagnostic Approaches for the Assessment of Equine Chronic Pulmonary Disorders. Journal of Equine Veterinary Science, 31, 400-410. http://dx.doi.org/10.1016/j.jevs.2011.03.018

[25] Hodgson, J.L. and Hodgson, D.R. (2007) Collection and Analysis of Respiratory Tract Samples. In: McGorum, B.C., Dixon, P.M., Robinson, N.E. and Schumacher, J., Eds., Equine Respiratory Medicine and Surgery, Saunders, Philadelphia, 119-150. http://dx.doi.org/10.1016/B978-0-7020-2759-8.50014-3

[26] Koblinger, K., Nicol, J., McDonald, K., Wasko, A., Logie, N., Weiss, M. and Léguillette, R. (2011) Endoscopic Assessment of Airway Inflammation in Horses. Journal of Veterinary Internal Medicine, 25, 1118-1126. http://dx.doi.org/10.1111/j.1939-1676.2011.00788.x

[27] Viel, L. and Hewson, J. (2001) BAL Cytology in Horses with Exercise Intolerance: What Does It Tell Us? Proceedings of the 2nd World Equine Airways Symposium, Edinburgh, CD-ROM. 
[28] Sánchez, A., Couëtil, L.L., Ward, M.P. and Clark, S.P. (2005) Effect of Airway Disease on Blood Gas Exchange in Racehorses. Journal of Veterinary Internal Medicine, 19, 87-92. http://dx.doi.org/10.1111/j.1939-1676.2005.tb02663.x

[29] McKane, S.A., Canfield, P.J. and Rose, R.J. (2008) Equine Bronchoalveolar Lavage Cytology: Survey of Thoroughbred Racehorses in Training. Australian Veterinary Journal, 70, 401-404. http://dx.doi.org/10.1111/j.1751-0813.1993.tb06072.x

[30] Araya, O., Palma, P., Salvi, M., Bustamante, H. and Vits, L. (2005) Endoscopic Determination of Exercise-Induced Pulmonary Haemorrhage in Chilean Criollo Horses. The Veterinary Journal, 169, 311-313. http://dx.doi.org/10.1016/j.tvjl.2004.02.002

[31] Sweeney, C.R. and Humber, K.A. (1992) Cytologic Findings of Trachea-Bronchial Aspirates from 66 Thoroughbred Racehorses. American Journal of Veterinary Research, 53, 1172-1175.

[32] Derksen, F.J., Brown, C.M., Sonea, I., Darien, B.J. and Robinson, N.E. (1989) Comparison of Transtracheal Aspirate and Bronchoalveolar Lavage Cytology in 50 Horses with Chronic Lung Disease. Equine Veterinary Journal, 21, 23-26. http://dx.doi.org/10.1111/j.2042-3306.1989.tb02084.x

[33] Hoffman, A.M. (2008) Bronchoalveolar Lavage: Sampling Technique and Guidelines for Cytologic Preparation and Interpretation. Veterinary Clinics of North America: Equine Practice, 24, 423-435. http://dx.doi.org/10.1016/j.cveq.2008.04.003

[34] Anderson, S., Shires, V.L., Wilson, R.A. and Mountford, A.P. (1999) Formation of Multinucleated Giant Cells in the Mouse Lung Is Promoted in the Absence of Interleukin-12. American Journal of Respiratory Cell and Molecular Biology, 20, 371-378. 10.1165/ajrcmb.20.3.3317

[35] Helming, L. and Gordon, S. (2007) Macrophage Fusion Induced by IL-4 Alternative activation Is a Multistage Process Involving Multiple Target Molecules. European Journal of Immunology, 37, 33-42. http://dx.doi.org/10.1002/eji.200636788

[36] Franklin, S.H., Naylor, J.R. and Lane, J.G. (2006) Videoendoscopic Evaluation of the Upper Respiratory Tract in 93 Sport Horses during Exercise Testing on a High-Speed Treadmill. Equine Veterinary Journal, 36, 540-545. http://dx.doi.org/10.1111/j.2042-3306.2006.tb05601.x

[37] Davidson, E.J. and Martin, B.B. (2003) Diagnosis of Upper Respiratory Tract Diseases in the Performance Horse. Veterinary Clinics North American: Equine Practice, 19, 51-62. http://dx.doi.org/10.1016/S0749-0739(02)00066-4

[38] Semeco, E., Rodrígues, M., Básalo, A., Aranguren, J. and Fernández, M. (2011) Prevalencia de las enfermidades obstructivas del tracto respiratorio superior em equinos Purosangres de Carreras. Revista Científica, 21, 215-223.

[39] Erickson, H.H. and Poole, D.C. (2002) Exercise-Induced Pulmonary Hemorrhage. In: Lekeux, P., Ed., Equine Respiratory Diseases, Ithaca, New York.

[40] Baccarin, R.Y.A. (2005) Diagnóstico e tratamento das pneumopatias de esforço. II Simpósio Internacional do Cavalo Atleta e IV Semana do Cavalo-SIMCAV, Belo Horizonte, 12-28.

[41] Neto, J.B.A. (2009) Avaliação endoscópica do trato respiratório superior e inferior proximal em cavalos de vaquejada. Ph.D. Thesis, Universidade Federal Rural de Pernambuco, Recife. 
Scientific Research Publishing (SCIRP) is one of the largest Open Access journal publishers. It is currently publishing more than 200 open access, online, peer-reviewed journals covering a wide range of academic disciplines. SCIRP serves the worldwide academic communities and contributes to the progress and application of science with its publication.

Other selected journals from SCIRP are listed as below. Submit your manuscript to us via either submit@scirp.org or Online Submission Portal.
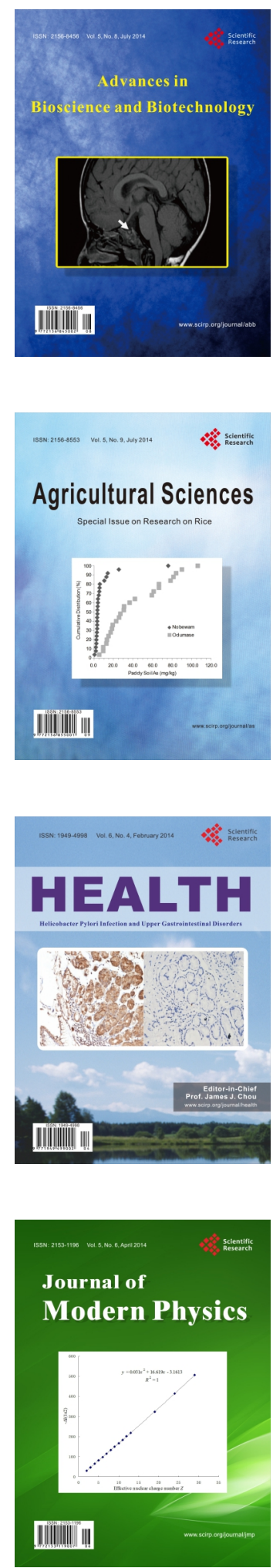
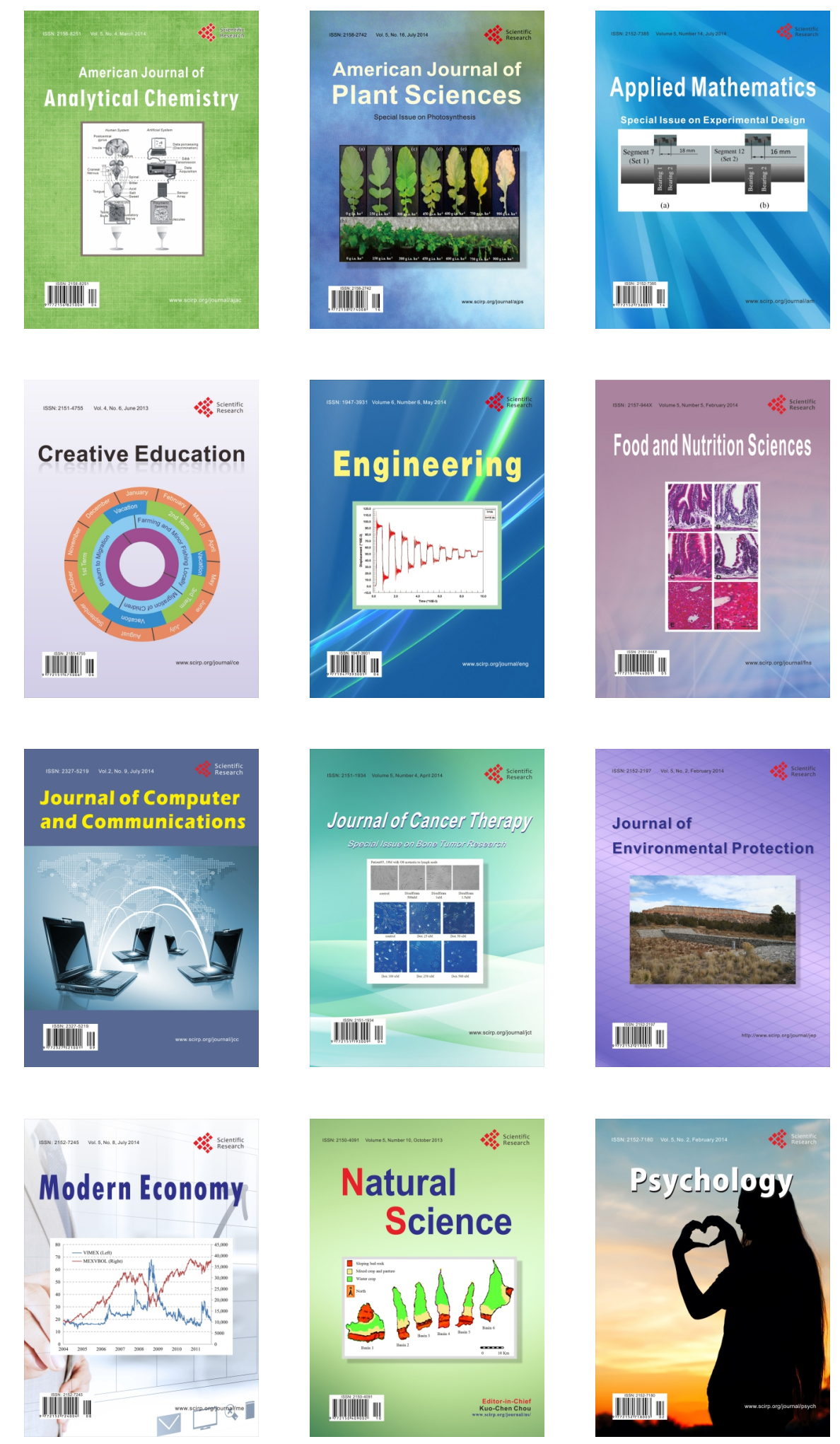